\title{
GaN-based Photodiodes on Silicon Substrates
}

\author{
L.S. Chuah ${ }^{1}$ and Z. Hassan ${ }^{2}$ \\ ${ }^{1}$ Physics Section, School of Distance Education, Universiti Sains Malaysia, 11800 Penang, \\ ${ }^{2}$ Nano-Optoelectronics Research and Technology Laboratory, School of Physics, \\ Universiti Sains Malaysia, 11800 Penang, \\ Malaysia
}

\section{Introduction}

GaN-based or the III-V nitrides materials are wide band gap semiconductor materials with dormant utilizations in optoelectronic as well as in electronic devices operating at high power and high temperature conditions. Silicon (Si) is one of the most common elements of the earth crust and the substrates are of very low price and are available in very large size due to its mature development and large-scale production. The thermal conductivity is higher than that of sapphire and is close to that of GaN. The crystal perfection of $\mathrm{Si}$ is better than that of any other substrate material and it has good thermal stability under GaN epitaxial growth condition. The growth of $\mathrm{GaN}$ on $\mathrm{Si}$ enables the possibility of integrating GaN optoelectronics devices with Si-based electronics. However, despite much effort, there is no significant breakthrough that has been obtained because of the high density of dislocations in these materials leading to a rapid degradation of all devices fabricated so far. In contrast, the performances of GaN-based devices are known to be quite acceptable despite the large density of dislocations present in the films. There are only few reports on GaN photodetectors on $\mathrm{Si}(111)$, including PN heterojunction photodiode, metalsemiconductor-metal (MSM) photodetectors, and Schottky photodiodes. This chapter will present the fabrication and characterization aspects of GaN-based photodiodes on $\mathrm{Si}$ substrates.

Photodetectors operating in the UV and with a visible blind behavior have drawn great attention in recent years, with a number of applications in both civil and military industries which include detection of missile plumes, flame sensors, engine control, solar UV monitoring, source calibration, UV astronomy, and secure space-to-space communications (Keem et. al., 2004; Hassan et. al., 2004).

Contrast to $\mathrm{Si}$, gallium nitride $(\mathrm{GaN})$ has wide band gap, outstanding thermal stability, small dielectric constant, chemical inertness and radiation hardness. These features make it an typical choice for use in fabricating high frequency, high power electronic devices. Furthermore, the essential preference of III-V nitrides detectors above competing devices based on semiconductors with smaller bandgaps is the long wavelength response cut-off, which is straightly associated to the bandgap of the material in the dynamic area and consequently, does not involve external filters (BenMoussa et. al., 2008). Gallium nitride $(\mathrm{GaN})$ is of distinguished interest because of its great UV photoresponse, well-founded mixture techniques, and the capability of operating at high temperature and in harsh 
circumstances. Dissimilar to wide band gap photodetector, the forward surface of a vacuum ultraviolet silicon photodiode is coated with filter materials to limit the sensitivity of the silicon to a much narrower band in the vacuum ultraviolet (VUV) because one significant shortcoming of Si photodiodes for certain VUV applications is the inherent broadband response extending from $x$-rays to the near infrared, which is undesirable.

Mainly, photodetectors can be assorted in accordance with the type of optical to electrical conversion effect. A photoelectric detector is based on the process of photon absorption by the material with the release of an electron-hole pair. In the case where the photo-generated electron is further emitted out of the material in which they become available for collection or multiplication, the device is called a photo emissive detector which is based on the external photoelectric effect. Some examples of photo emissive detectors are like photomultipliers, vacuum photodiodes, and image intensifier tubes. However, if there is no emission taking place but the photo generated electron-hole pair is available for the current circulation in the external circuit; then this is called an internal photoelectric effect detector which is the characteristic of all semiconductor photodetectors.

A p-n junction photodiode operates under reverse bias by the absorption of incident photons with energy larger than the energy gap $\left(E_{g}\right)$, therefore producing electron-hole pairs in the material on both sides of the junction. The holes and electrons produced in a diffusion length from the junction get to the depletion region by diffusion. Over there, the electron-hole pairs are separated by the firm electric field and minority carriers are readily accelerated to become majority carriers on the other side, generating a photocurrent. The carrier diffusion step in this process is time consuming and should be eliminated if possible. Consequently, it is useful that the distance across of the depletion region be wide enough so that nearly all of the photons are absorbed within the depletion region rather than in the neutral $p$ and $n$ regions. Several types of $\mathrm{GaN}$ ultraviolet detectors have been reported, for example, photoconductive, p-n junction, $p-\Pi-n$, Schottky barrier, MSM, and heterojunction in recent years. For metal-semiconductor contacts, the ohmic contact is needed for connections to devices because of its linear current-voltage (I-V) characteristics in both biasing directions.

Aluminium nitride, AlN (wurtzite structure type) has specific physical properties like high thermal conductivity (91-190 W/m-K), large breakdown electric field, high electrical resistivity (1011-1014 $\Omega \mathrm{cm}$ ), high melting point and large energy gap (Qioa et. a., 2000). Its application as a component of refractory ceramics or buffer layers for GaN epilayers grown on sapphire are widely known. In the last decade considerable attention arose in the use of thin films of AlN for various applications, from coatings for magneto-optic media, to thin films transducers and GHz-band surface acoustic wave devices. AlN is a broad band gap semiconductor; its characteristics are similar to those of an insulator with a high dielectric constant, large breakdown electric, and field good conductivity. Consequently, AlN could be the best insulator to block the leakage current. Before that, it has been demonstrated that one can decrease gate leakage current and interface state density in GaN-based effect transistor by using the AlN thin layer (Yu. et. al., 2006).

In the present work, we fabricated the p-GaN/n-Si heterojunction photodiode to observe the photoelectric effects. Besides that, the impacts of thermal annealing on GaN Schottky barrier photodiode with a thin AIN cap layer are also examined, principally because of the high thermal stability of $\mathrm{GaN}$ that has prompted us to bring out the best from thermal treatment to the electrical characteristics of the UV photodetectors. Thermal annealing has been effective in reducing the dark current in Schottky photodiodes which is the discussion that we are 
addressing in this text. We also have investigated growth of $\mathrm{Al}_{0.09} \mathrm{Ga}_{0.91} \mathrm{~N}$ epilayers grown on silicon (111). Also reported is our attempt to fabricate and characterize metal-semiconductormetal (MSM) photodiode based on these films. The effect of post annealing in oxygen ambient on the electrical properties of $\mathrm{Ni} / \mathrm{Al}_{0.09} \mathrm{Ga}_{0.91} \mathrm{~N}$ is studied by $I-V$ measurement.

\section{Operation principle}

Photodiodes are illuminated devices utilized to identify optical signals straight throughout electronics processes, ordinarily performance under photoconductive method. The performance contains a couple of steps: (i) charge carrier transport; (ii) carrier formation by light absorption, of which the photon need only have greater energy than that of the band gap of device materials; and (iii) the interplay of current with the external circuit to provide the output voltage signal. The supreme wavelength of the light that can generate electrons and holes is found as (Sze,1981):

$$
\lambda=\mathrm{hc} / \mathrm{E}_{\mathrm{g}}
$$

where $h$ is the Planck's constant; $c$, the velocity of light; and $E_{g}$ is the bandgap of the semiconductor material. The devices function under reverse bias for the photoconductive mode for the purpose of decreasing the heterojunction capacitance and the giving up of carriers because of the larger depletion width (Luo et. al., 2006).

The I-V characteristic of a photodiode without incident light intensity is similar to a curve of a conventional diode rectification. When a reverse bias is applied, a small reverse current appears which is related to dark current. When the photodiode is irradiated with optical distribution, the $I-V$ curve was changed by the number of photocurrent. A schematic view of the typical energy band diagram of the $\mathrm{p}-\mathrm{GaN} / \mathrm{n}-\mathrm{Si}$ structure and the theory of the photodiode is shown in Fig. 1. When the photon energy of the incident light is higher than the bandgap of $\mathrm{GaN}(3.4 \mathrm{eV})$, electron-holes pairs are generated inside $\mathrm{GaN}$ by light absorption. Simultaneously, the electron-hole pairs are separated by the electric field inside the depletion region of $\mathrm{GaN}$ to create photocurrent. The illumination also produces electrons and holes in the inert $n$-type and $p$-type zones, a few of which can diffuse to the depletion layer, contributing to the photocurrent (Philippe et. al., 1999). In real devices, a barrier layer at the interface of GaN might be existing due to the very thin of layer native silicon dioxide that is not drawn in Fig.1.

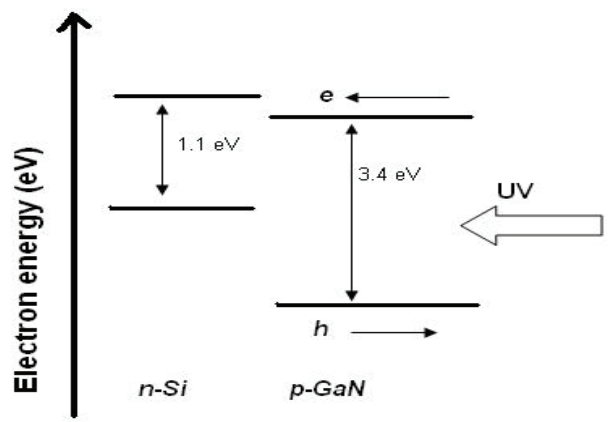

Fig. 1. Schematic energy band diagram of the $\mathrm{p}-\mathrm{GaN} / \mathrm{n}-\mathrm{Si}$ structure. 


\section{Experiment}

For the first sample, a heterojunction of Mg-doped p-type crystalline gallium nitride (GaN) were grown on n-type $\mathrm{Si}(111)$ by radio frequency nitrogen plasma-assisted MBE (PAMBE). Sample nominally consisted of $0.10 \mu \mathrm{m}$ AlN as a buffer layer followed by $0.23 \mu \mathrm{m} \mathrm{Mg}$ doped GaN with carrier concentration of $\sim 2 \times 10^{18} \mathrm{~cm}^{-3}$ as determined by Hall Effect measurement and the electrical conduction of all the samples was p-type.

For the wafer cleaning process prior to metallization of the contact metal, the GaN samples were dipped in a 1:20 $\mathrm{NH}_{4} \mathrm{OH}: \mathrm{H}_{2} \mathrm{O}$ solution for $15 \mathrm{~s}$ followed by a $10 \mathrm{~s}$ dip in a 1:50 HF: $\mathrm{H}_{2} \mathrm{O}$ solution. Then, it was rinsed with distilled water and blown dry with a nitrogen gas blower. Metal contact was sputtered by a sputtering system onto the backside and front-side, respectively. Here, to provide a low contact resistance of electrode, Ni/ Ag (250 nm/600 nm) dots $(250 \mu \mathrm{m}$ in diameter) was deposited on the Mg-doped GaN layer at a corner, as shown in Fig. 2. In the same manner, a large area ohmic contact of $\mathrm{Al} / \mathrm{Ti}(250 \mathrm{~nm} / 600 \mathrm{~nm})$ was also deposited on the backside of the $\mathrm{Si}$ substrate to form the second electrode of the p-n diode. A couple of contacts were patterned on the back part of an isolated piece of the sample to verify ohmic contact formation.

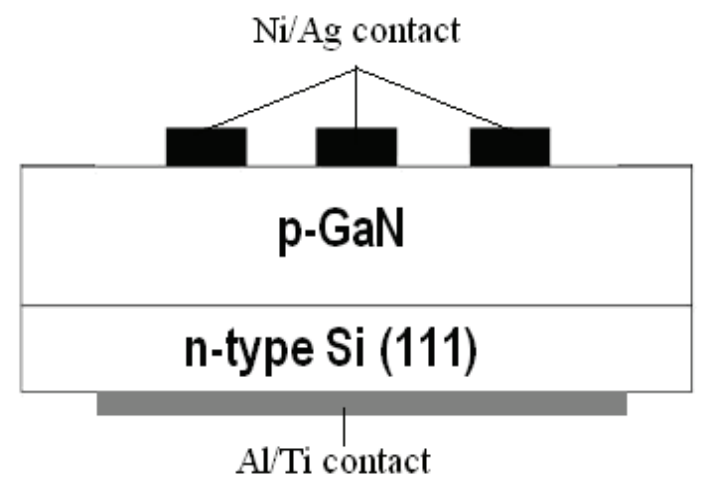

Fig. 2. Cross section view of the $\mathrm{p}-\mathrm{n}$ heterojunction diode sample.

After metallization, the samples were annealed in a tube furnace at $400^{\circ} \mathrm{C}$ under flowing nitrogen gas environment for duration of 10 minutes. The setup of the furnace is shown in Fig. 3. Nitrogen gas was purged into the tube during annealing to displace the room ambient inside the tube. Room ambient contains nitrogen molecules that may interfere with the ohmic contact formation. The gas was purged at a mass flow rate of approximately 4 L.min ${ }^{-1}$. The electrical behaviors of the contacts were analyzed by current-voltage (I-V) measurements. For the reverse bias configuration, negative bias was applied to the $\mathrm{p}-\mathrm{GaN}$ film. The measurements were performed with or without an Hg-lamp onto GaN surface. The Hg-lamp illumination was placed vertically and $3 \mathrm{~cm}$ away from the sample. The light beam size was large enough to barely cover the GaN surface.

For the second set sample, unintentionally doped n-type GaN $(800 \mathrm{~nm})$ layers were grown, followed by subsequent thin AlN cap layer $(50 \mathrm{~nm})$ grown on the GaN surface. GaN-based Schottky photodiodes with a thin AlN cap layer were then fabricated. 


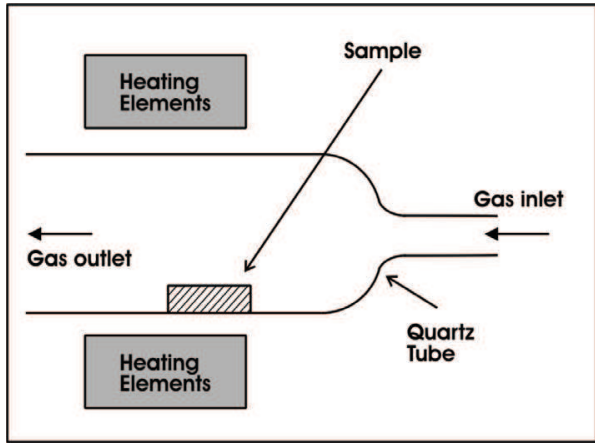

Fig. 3. Setup of tube furnace for thermal annealing.

Following surface treatment, aluminium $(100 \mathrm{~nm})$ metal stripes were coated on the sides of the samples as ohmic contacts by thermal evaporation technique. Contacts were then annealed in the furnace at $400{ }^{\circ} \mathrm{C}$ for $10 \mathrm{~min}$ under flowing nitrogen gas environment. $I-V$ measurement was performed to confirm the ohmic behavior of the contacts. Consequent to the ohmic contacts deposition, $\mathrm{Ni}(150 \mathrm{~nm})$ was deposited as the Schottky contact metal for all of the fabricated devices. The metal mask applied for Schottky contacts fabrication encompasses a pattern of dots with diameter of $200 \mu \mathrm{m}$. Both contacts were formed on the uppermost surface of the sample.

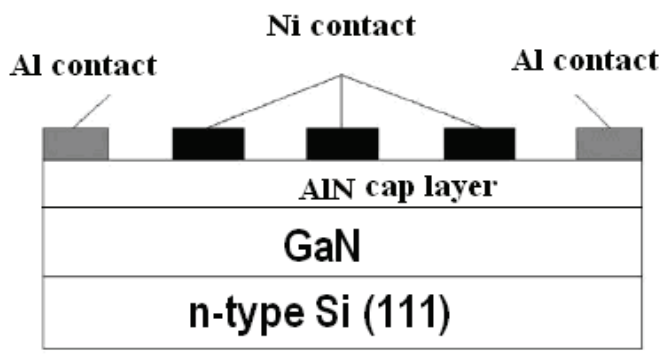

Fig. 4. Cross section view of ohmic and Schottky contacts of a typical GaN-based Schottky photodiodes using a thin AlN cap layer.

The fabricated photodiodes were then annealed in nitrogen ambient at temperatures from $500-700{ }^{\circ} \mathrm{C}$ in a typical tube furnace. For sample (photodiode) annealed at $500{ }^{\circ} \mathrm{C}$, the annealing duration was $15 \mathrm{~min}$, while the $600{ }^{\circ} \mathrm{C}$ sample was annealed for $5 \mathrm{~min}$ and $2 \mathrm{~min}$ for the $700{ }^{\circ} \mathrm{C}$ sample (Lee et. al., 2005). Photocurrent and dark current of the fabricated photodiodes were then measured by Keithley high-voltage-source-measure-unit model 237semiconductor parameter analyzer. The ideality factors $(n)$ and effective Schottky barrier heights (SBHs) are deduced from the I-V measurement.

For the third set sample, sample nominally consisted of $0.20 \mu \mathrm{m}$ low temperature nucleation layer AlN followed by $0.23 \mu \mathrm{m}$ of unintentionally doped n-type AlGaN (Fig. 5). The Al content of the sample was measured to be $9 \%$ from high resolution XRD (PANalytical $X^{\prime}$ pert MRD) simulation. Following surface treatment, Ni Schottky contacts were deposited by thermal evaporation using a metal mask in patterning of the contact structure. 
MSM photodiode is a planar device consisting of two fork-shaped interdigitated contacts on the semiconductor surface. These contacts performs as back to back Schottky contacts with finger spacing of $400 \mu \mathrm{m}$, fingers width of $230 \mu \mathrm{m}$, and the length of each electrode was about $3.3 \mathrm{~mm}$ (Lee et. al., 2005). It consists of 4 fingers at each electrode as shown in Fig. 6. The fabricated photodiodes were then annealed at temperatures from $400-700{ }^{\circ} \mathrm{C}$ in a conventional tube furnace in flowing oxygen environment. The annealing duration for the samples annealed at temperatures from $400{ }^{\circ} \mathrm{C}$ to $500{ }^{\circ} \mathrm{C}$ was 15 minutes, while the $600{ }^{\circ} \mathrm{C}$ samples were annealed for 5 minutes, and 2 minutes for the $700{ }^{\circ} \mathrm{C}$ samples. The effective Schottky barrier heights (SBHs) are deduced from $I-V$ measurement assuming the results can be described by the standard thermionic emission equation.

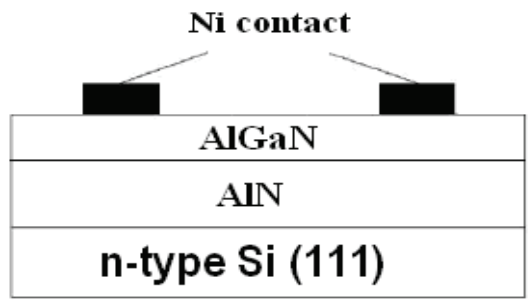

Fig. 5. Cross section view of the Ni Schottky contacts on AlGaN sample.

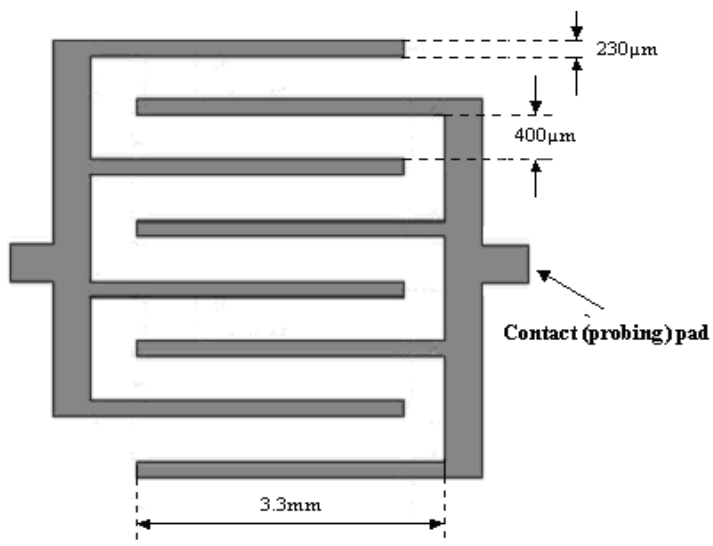

Fig. 6. Schematic diagram of the metal-semiconductor-metal (MSM) structure (Lee et. al., 2005)

\section{Results and discussions}

Studies of the I-V characteristics of the fabricated p-GaN/n-Si structure revealed a good p-n heterojunction as shown in Fig. 7. The I-V relationship for a heterojunction is given by (BenMoussa et. al., 2008):

$$
I=I_{s}\left[\exp \left(\frac{q V}{K_{B} T}\right)-1\right]
$$


where $I$ is the current; $V$ is the applied voltage across the heterojunction from $\mathrm{p}$-side to $\mathrm{n}$ side; $K_{B}$ is the Boltzmann constant; $I_{S}$ is the saturation current; and $T$ is the absolute temperature. The typical $I-V$ rectifying characteristic in the dark (without light illumination) at room temperature is observed in Fig. 7 to evaluate the turn on voltage. A pronounced rectifying diode-like behavior with turn on voltage of $0.8 \mathrm{~V}$ can be seen. The forward current was as high as $0.012 \mathrm{~A}$ at $8 \mathrm{~V}$ forward bias.

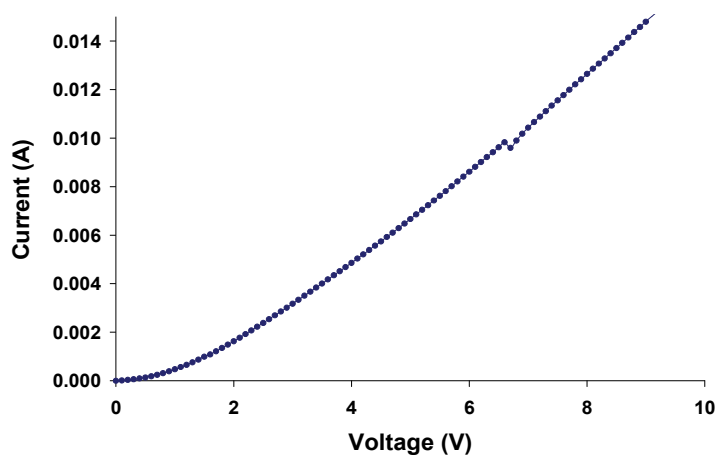

Fig. 7. I-V characteristics of the heterojunction in dark at room temperature (Chuah et. al., 2008a)

At the wavelength of $365 \mathrm{~nm}$, the UV photo measurement was performed using an $\mathrm{Hg}$ lamp. The mechanism of the crystalline-based $\mathrm{p}-\mathrm{GaN} / \mathrm{n}-\mathrm{Si}$ diode is described as follows. Since the photon energy is larger than the bandgap of GaN, UV light source was absorbed by the GaN thin film producing electron-hole pairs, which were isolated by the electric field inside the $\mathrm{GaN}$ thin film contributing to the raise of the external current. Before p-GaN an $\mathrm{n}$-Si are in contact, $\mathrm{p}-\mathrm{GaN}$ has high concentration of holes and few electrons compared to that of n-Si. On contacting, diffusion of carriers will take place at concentration gradient near to the junction. The holes will diffuse from $\mathrm{p}-\mathrm{GaN}$ to $\mathrm{n}-\mathrm{Si}$ and negative space charge will remain behind in $\mathrm{p}-\mathrm{GaN}$ near the junction.

From the p-GaN side, holes diffuse into the n-Si side, and electrons diffuse from n-Si into pGaN. Although the electrons and holes can move to the opposite side of the junction, the donors and acceptors are fixed in space. When electrons diffuse from the n-Si to the p-GaN side, they drop behind uncompensated donor ions in the n-Si material, and holes leaving the $\mathrm{p}-\mathrm{GaN}$ region produce uncompensated acceptors. The diffusion of electrons and holes from the vicinity of the junction establishes a region of positive space charge near the $\mathrm{n}$ side of the junction and negative charge near the $p$ side. An electric field is constructed at the interface. Photocurrents are directly gained (An Doan et. al., 2002).

At zero voltage bias, the energy gaps $\left(\mathrm{E}_{\mathrm{g}}\right)$ for $\mathrm{GaN}$ and $\mathrm{Si}$ are $3.4 \mathrm{eV}$ (Miskys et. al., 2003) and $1.12 \mathrm{eV}$, respectively. The electron affinity for $\mathrm{GaN}$ is approximated as $4.10 \mathrm{eV}$ (Yeh et. al., 2007). However the electron affinity for $\mathrm{Si}$ is $3.95 \mathrm{eV}$ (Edgar et. al., 1999). The energy barrier $\Delta \mathrm{E}_{\mathrm{c}}$ for electrons is $\Delta \mathrm{E}_{\mathrm{c}}=\mathrm{X}_{\mathrm{GaN}}-\mathrm{X}_{\mathrm{Si}}=(4.10-3.95) \mathrm{eV}=0.15 \mathrm{eV}$, while the energy barrier $\Delta \mathrm{E}_{\mathrm{v}}$ for holes is $\Delta \mathrm{E}_{\mathrm{v}}=\mathrm{E}_{\mathrm{g}, \mathrm{GaN}}+\Delta \mathrm{E}_{\mathrm{c}}-\mathrm{E}_{\mathrm{g}, \mathrm{Si}}=(3.4+0.15-1.12) \mathrm{eV}=2.43 \mathrm{eV}$. Consequently, the energy barrier for holes $\left(\Delta \mathrm{E}_{\mathrm{v}}\right)$ is 16 times more than the barrier for electrons $\left(\Delta \mathrm{E}_{\mathrm{c}}\right)$ (He et. al., 2007).

When a reverse bias is used, holes confront $\Delta \mathrm{E}_{\mathrm{v}}$, producing a low current. In adverse, when a forward bias is applied, the electron only require to surmount a much smaller potential 
barrier $\left(\Delta \mathrm{E}_{\mathrm{c}}\right)$, hence presenting rise to the rectifying effect. These arguments are for the ideal case, and direct measurements are required to ascertain the exact band structure of the heterojunction (He et. al., 2007).

In addition, crystalline GaN photodiodes were designed to be responsive to optical source. The UV photocurrent measurement was performed using an Hg-lamp. Because the photon energy is higher than the bandgap of GaN ( $364 \mathrm{~nm}$ wavelength), UV light was absorbed by the crystalline $\mathrm{GaN}$ creating electron-hole pairs, which were further separated by the electric field inside GaN contributing to the increase of the external current. Since the bandgap of $\mathrm{p}-\mathrm{GaN}$ layer is larger than that of the substrate, band-to-band photo excitation cannot take place in this layer (Luo et. al., 2006; Soci et. al., 2010).

In this work, reverse bias was used for the photodiode operation to maximize the depletion width, reduce the transit time, and the carrier loss because of recombination process in diffusion area. Photodiodes typically have high resistance under reverse bias. This resistance is reduced when light of an appropriate frequency illuminates on the junction to create additional free electron-hole pairs. Consequently, a reverse biased diode may be applied as a detector by observing the current running through it (He et. al., 2007).

The I-V characteristics are shown in Fig. 8, where clear rectifying behavior can be seen both in the dark and under UV illumination conditions. Clear response to UV illumination can be seen from Fig. 7 in the reverse-biased condition because of the photogeneration of additional electron-hole pairs. The magnitude of photocurrent improves with the increase of applied reverse bias because of enhanced carrier collection. The photocurrent is $2.0 \mathrm{~mA}$ with $-3 \mathrm{~V}$ reverse bias. On the other hand, the dark leakage current for the GaN photodiodes is weak $(0.8 \mathrm{~mA}$ in the $-3 \mathrm{~V}$ reverse bias). This behavior shows that $\mathrm{GaN}$ photodiodes can sensitively distinguish UV light to produce the measurable photocurrent response. The capability of the device is influenced by a few factors, including the presence of a thin native silicon dioxide barrier layer at the interface of the heterojunction that will decrease the photocurrent; and light loss by reflection and absorption of the top metal contact (Fahrettin et. al., 2008).

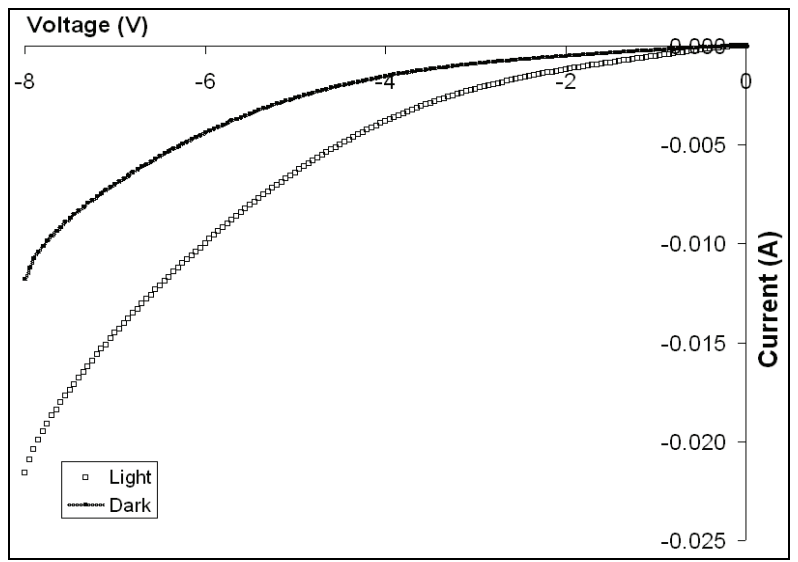

Fig. 8. The I-V characteristics of p-GaN/n-Si photodiodes. Photo-currents under illumination (light) are shown from the diodes (Chuah et. al., 2008a) 
For the second set sample, Fig. 9 show the $I-V$ characteristics of the Ni/AlN/GaN/AlN Schottky barrier photodiodes annealed at different temperatures. The higher turn-on voltage observed for all measurements under dark currents could be attributed to the highly resistive nature of the AIN cap layer. The dark current was $2.37 \times 10^{-3} \mathrm{~A}$ under $10 \mathrm{~V}$ applied bias for as deposited Ni/AlN/GaN/AlN Schottky diode. On the other hand, for Schottky diodes annealed at $500{ }^{\circ} \mathrm{C}, 600^{\circ} \mathrm{C}$, and $700^{\circ} \mathrm{C}$, the dark currents were $3.25 \times 10^{-4}, 4.97 \times 10^{-5}$, and $5.05 \times 10^{-5} \mathrm{~A}$, respectively, under $10 \mathrm{~V}$ applied bias.

By referring to Table 1, annealed samples exhibited more significant changes to the dark current characteristics compared to the as deposited Ni/AlN/GaN/AlN Schottky diode. This finding was further confirmed by measuring the contrast ratio of photo-current and dark current at $10 \mathrm{~V}$. The contrast ratio for annealed sample $\left(\right.$ at $700{ }^{\circ} \mathrm{C}$ ) and as deposited Schottky diode were found to be 25 and 2, respectively. High temperature $\left(600{ }^{\circ} \mathrm{C}\right.$ and 700 ${ }^{\circ} \mathrm{C}$ ) annealing treatment increased the barrier height as well as reduced the dark current as compared to the low temperature annealing $\left(500^{\circ} \mathrm{C}\right)$.

The $I-V$ characteristics of the Schottky diode, $\Phi_{\mathrm{B}}$ and $\mathrm{n}$, were determined assuming thermionic emission (Monroy et. al., 1998):

$$
\begin{aligned}
\mathrm{I} & =\mathrm{I}_{\mathrm{o}}[\exp \{\mathrm{qV} / \mathrm{nkT}\}-1] \\
\mathrm{I}_{\mathrm{O}} & =\mathrm{A}^{*} \mathrm{AT}^{2} \exp \left\{-\mathrm{q} \Phi_{\mathrm{B}} /(\mathrm{kT})\right\}
\end{aligned}
$$

where $I_{o}$ is the saturation current, $n$ is the ideality factor, $k$ is the Boltzmann's constant, $T$ is the absolute temperature, $\Phi_{B}$ is the barrier height, $A$ is area of the Schottky contact and $A^{*}$ is the effective Richardson coefficient. The theoretical value of $A^{*}$ can be calculated using

$$
\mathrm{A}^{*}=4 \pi \mathrm{m}^{*} \mathrm{qk}^{2} / \mathrm{h}^{3}
$$

where $h$ is Planck's constant and $m^{*}=0.27 m_{0}$ is the effective electron mass for AlN (Chen at. Al., 2004). The value of $A^{*}$ is determined to be $32.4 \mathrm{Acm}^{-2} \mathrm{~K}^{-2}$.

Using equation (3) and the theoretical value of $A^{*}$, under dark condition, the Schottky barrier height derived by the I-V method is $0.48 \mathrm{eV}$ for as deposited Ni/AlN/GaN/AlN Schottky diode. On the other hand, the effective barrier heights of $0.52 \mathrm{eV}, 0.55 \mathrm{eV}$, and 0.57 $\mathrm{eV}$ were obtained for Schottky diodes annealed at $500{ }^{\circ} \mathrm{C}, 600{ }^{\circ} \mathrm{C}$, and $700{ }^{\circ} \mathrm{C}$, respectively. In our earlier study, a thin AIN cap layer was incorporated in GaN Schottky diode to improve the effective Schottky barrier height and decreases the dark current. A barrier height of $0.52 \mathrm{eV}$ for typical Ni/GaN Schottky diode was increased to the effective barrier height of $0.63 \mathrm{eV}$ for Ni/GaN Schottky diode with thin AlN cap layer. The low dark currents in GaN Schottky barriers with the thin AIN cap layer might be attributed to the AlN cap layer, resulting in a higher potential barrier, compared to standard sample. The deleterious effect of the interface states near the metal/semiconductor interface may be reduced for the sample owing to the insertion of the AlN cap layer. It was established that AlN cap layers would completely suppress the dark current of the GaN Schottky diodes and resulted in improved device characteristics (Chuah et. al., 2008b).

In the last few years, various kinds of nitride-based photodetectors have been reported (Vivian et. al., 2010). Nevertheless, an opposing condition usually occurs, when large differences in the lattice constant and thermal expansion coefficient of GaN and silicon inevitably lead to high dislocation density in the GaN epitaxial layer. Such a result contributes to a large dark current and smaller photocurrent/dark current ratio for nitride- 
based Schottky barrier photodetctors. Despite, we attained low dark current from the GaN metal-semiconductor-metal photodiode with a 50-nm thick low temperature GaN barrier enhancement layer (Chuah et. al., 2008c).

With a panorama to decreasing the dark current of Schottky barrier photodetectors, metalinsulator-semiconductor (MIS) structures are for the present deeply investigated. In past reports, a number of gate dielectrics for example $\mathrm{SiO}_{2}$ have been used in MIS structures (Casey et. al., 1996; Gaffey et. al., 2001). Nevertheless, these insulators were all ex-situ deposited and the contamination might occur at the insulator/semiconductor interface. Consequently, we deposited an in-situ AlN cap layer by MBE in our study. Nevertheless, not much report on GaN-based Schottky barrier photodiodes capped with an AlN layer can be detected in the literature, to our knowledge.

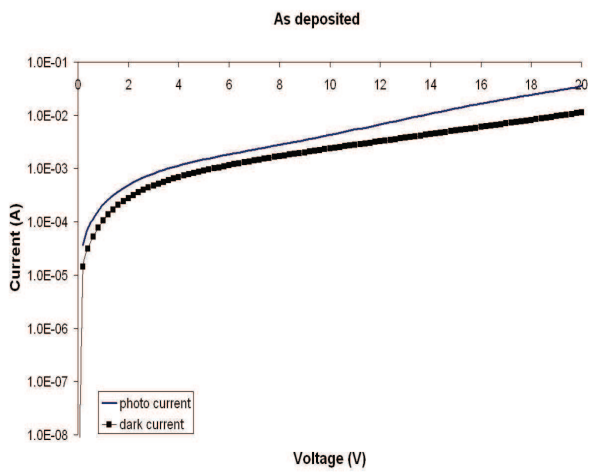

(a)

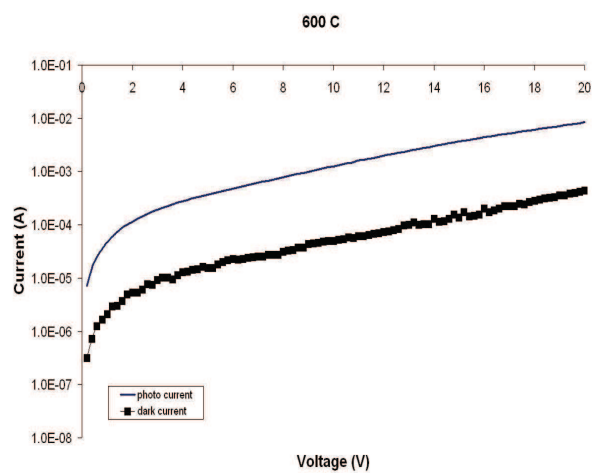

(c)

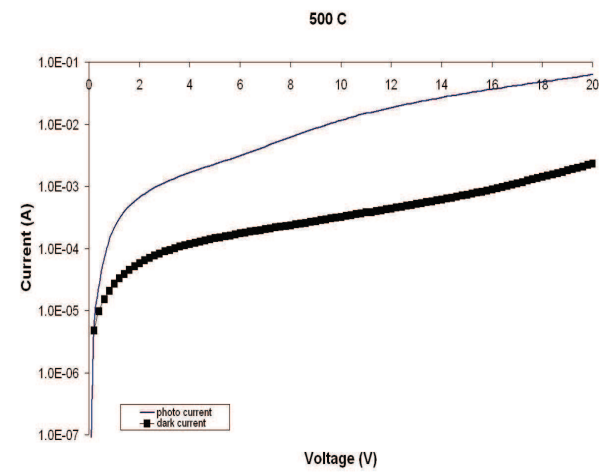

(b)

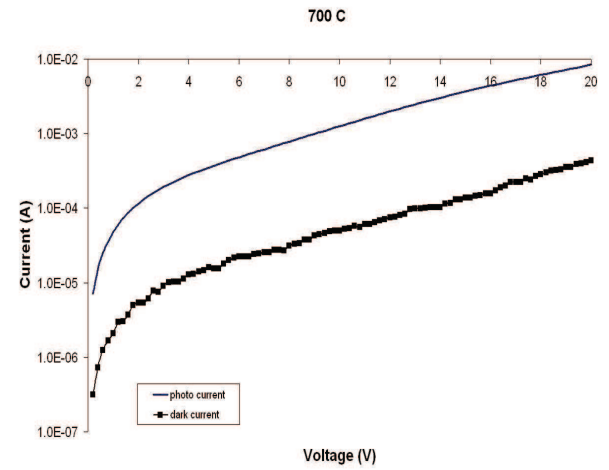

(d)

Fig. 9. I-V characteristics of the fabricated photodiodes annealed at different temperatures (a) as deposited, (b) $500^{\circ} \mathrm{C}$, (c) $600^{\circ} \mathrm{C}$, and (d) $700^{\circ} \mathrm{C}$ (Chuah et. al., 2009a)

According to Reddy (Reddy et. al., 2007), they hypothesized that the temperature dependence of Schottky barrier height maybe due to the changes of surface morphology of Pt films on the $\mathrm{n}-\mathrm{GaN}$ and variation of nonstochiometric defects at the interface. Khanna et al. (Khanna et. al., 2006) investigated temperature dependence of $\mathrm{W}_{2} \mathrm{~B}_{5}$-based rectifying contacts to $\mathrm{n}$-GaN and showed that the Schottky barrier height $(0.65 \mathrm{eV})$ increased with annealing temperature up to 
$200{ }^{\circ} \mathrm{C}$. Wang et al. (Wang et. al., 2003) investigated that the variation of barrier height upon annealing could be ascribed to variation of surface morphology and inequality of nonstochiometric defects at the interface vicinity. In the current work, the increase of the Schottky barrier height could be because of the decrease of nonstochiometric defects in the metallurgical interface (Wang et. al., 2003). The region involving the defects could be decreased because of the interdiffusion of $\mathrm{Ni}$ and $\mathrm{Al}$. Hence, the consumption of the defect region is followed by a raise in the value of the Schottky barrier height extracted from the I-V characteristics for the samples annealed from $500^{\circ} \mathrm{C}$ to $700{ }^{\circ} \mathrm{C}$.

\begin{tabular}{|c|c|c|c|c|}
\hline $\begin{array}{c}\text { Temperature } \\
\left({ }^{\circ} \mathrm{C}\right)\end{array}$ & $\begin{array}{c}\text { Samples } \\
\text { (photodiodes) }\end{array}$ & $\begin{array}{c}\text { Ideality } \\
\text { factor, } \\
n\end{array}$ & $\begin{array}{c}\text { Barrier height, } \\
\Phi_{\mathrm{b}}(\mathrm{eV})\end{array}$ & $\begin{array}{c}\text { Current at 10V } \\
(\mathrm{A})\end{array}$ \\
\hline \multirow{2}{*}{ As deposited } & dark & 1.08 & 0.48 & $2.37 \times 10^{-3}$ \\
\cline { 2 - 5 } & illumination & 1.10 & 0.46 & $4.29 \times 10^{-3}$ \\
\hline \multirow{2}{*}{$500^{\circ} \mathrm{C}$} & dark & 1.07 & 0.52 & $3.25 \times 10^{-4}$ \\
\cline { 2 - 5 } & illumination & 1.08 & 0.50 & $1.15 \times 10^{-2}$ \\
\hline \multirow{2}{*}{$600^{\circ} \mathrm{C}$} & dark & 1.03 & 0.55 & $4.97 \times 10^{-5}$ \\
\cline { 2 - 5 } & illumination & 1.04 & 0.53 & $1.20 \times 10^{-3}$ \\
\hline \multirow{2}{*}{$700^{\circ} \mathrm{C}$} & dark & 1.05 & 0.57 & $5.05 \times 10^{-5}$ \\
\cline { 2 - 5 } & illumination & 1.04 & 0.53 & $2.00 \times 10^{-3}$ \\
\hline
\end{tabular}

Table 1. Summary of the dark and photo-current (I-V) characteristics of the samples annealed at different temperatures.

As generally known, chemical reaction between the metal and the semiconductor interfaces can play an important role in the electrical properties of metal/semiconductor contact. The change in the barrier height of Ni/AlN/GaN/AlN Schottky contact with annealing temperature may also be ascribed to the interfacial reaction occurring between metals and AlN and their alloys which extend to AlN films. These interfacial layers might have dissimilar work functions than the Ni/AIN contact layers, which is responsible for the observed increase of barrier height (Lee et. al., 2006).

From the value of the ideality factors that we have obtained, the deviation of the diodes' ideality factor from unity may be due to tunneling effects, image force, and edge leakage. Furthermore, a unique value of ideality factor could be associated with a given set of diode conditions like temperature, bias, and doping. From the literature, the Schottky barrier heights varied widely from 0.50 to $1.15 \mathrm{eV}$ for $\mathrm{Ni}$, depending on the measuring methods, doping concentration and quality of the GaN (Schmitz et. al., 1996; Kalinina et. al., 1997). This also suggests that the metal work function should not be the only factor affecting the Schottky characteristics of the diodes (Kalinina et. al., 1997).

For the third set sample, a Schottky contact behaviour could be more closely described by the equation which takes into account the barrier height lowering because of electric field, tunneling effects, the presence of an interfacial layer, and carrier recombination in the space charge region of the metal-semiconductor contact as given by (Rideout et. al., 1975; Abdulmecit et. al., 1992)

$$
\mathrm{I}=\mathrm{I}_{0} \exp \left(\frac{\mathrm{eV}}{\mathrm{nkT}}\right)\left[1-\exp \left(\frac{-\mathrm{eV}}{\mathrm{kT}}\right)\right]
$$


where $\mathrm{I}$ is the current, $\mathrm{I}_{0}$ is the saturation current, $\mathrm{V}$ is the bias voltage, and $\mathrm{n}$ is the ideality factor. The expression for the saturation current, $\mathrm{I}_{0}$ is

$$
\mathrm{I}_{0}=\mathrm{AA}^{*} \mathrm{~T}^{2} \exp \left(\frac{-\mathrm{q} \Phi_{\mathrm{b}}}{\mathrm{kT}}\right)
$$

where A is the Schottky contact area, and the theoretical value (Hacke et. al., 1993) of $A^{*}$ for $\mathrm{GaN}$ is $\sim 26.4 \mathrm{Acm}^{-2} \mathrm{~K}^{-2}$. Here, the theoretical value of $\mathrm{A}^{*}$ for $\mathrm{Al}_{0.09} \mathrm{Ga}_{0.91} \mathrm{~N}$ can be estimated by using the relation $A^{*}=4 \Pi q m^{*} k^{2} / h^{3}$ where $h$ is Planck's constant and $m^{*}$ is the effective electron mass for $\mathrm{AlGaN}$. As there has not been any references or reported experimental results of the effective mass of electron in $\mathrm{AlGaN}$, therefore $\mathrm{m}^{*}$ for $\mathrm{Al}_{\mathrm{x}} \mathrm{Ga}_{1-\mathrm{x}} \mathrm{N}$ with different $x$ is estimated by a linear interpolation from the theoretical value of $\mathrm{m}^{*}=0.35 \mathrm{~m}_{0}$ for AlN (Kim et. al., 1997) and $\mathrm{m}^{*}=0.22 \mathrm{~m}_{0}$ for GaN (Piotr et. al., 1997). Here, $\mathrm{m}_{0}$ is the free electron mass. From the equation as being mentioned above, $\mathrm{A}^{*}$ for $\mathrm{Al}_{0.09} \mathrm{Ga}_{0.91} \mathrm{~N}$ is estimated to be $27.9 \mathrm{Acm}^{-2} \mathrm{~K}^{-2}$. However, it should be noted that a large variation in $\mathrm{A}^{*}$ does not have a significant influence on the $\Phi_{\mathrm{B}}$ value that is to be determined (Liu et. al., 1998). Equation (6) can be written in the form of

$$
\frac{\mathrm{I} \exp (\mathrm{eV} / \mathrm{kT})}{\exp (\mathrm{eV} / \mathrm{kT})-1}=\mathrm{I}_{0} \exp (\mathrm{eV} / \mathrm{nkT})
$$

At $\mathrm{T} \leq 370 \mathrm{~K}$ and when $\mathrm{V} \leq-0.5 \mathrm{~V}$, equation (8) can be simplified to (Averine et. al., 2000)

$$
\begin{gathered}
\operatorname{Iexp}\left(\frac{\mathrm{eV}}{\mathrm{kT}}\right)=\mathrm{I}_{0} \exp \left(\frac{\mathrm{eV}}{\mathrm{nkT}}\right) \\
\ln \left[\operatorname{Iexp}\left(\frac{\mathrm{eV}}{\mathrm{kT}}\right)\right]=\ln \mathrm{I}_{0}+\frac{\mathrm{eV}}{\mathrm{nkT}}
\end{gathered}
$$

The plot of $\ln [\operatorname{Iexp}(\mathrm{eV} / \mathrm{kT})]$ vs $\mathrm{V}$ should give a straight line with the slope $=\mathrm{e} / \mathrm{nkT}$ and $\mathrm{y}-$ intercept at $\ln \mathrm{I}_{0}$. Using equation (7), the ideality factor (n) and Schottky barrier height (SBH) were determined by the $I-V$ method.

Figures 10 show the I-V characteristics of Ni/AlGaN photodetectors under dark and illumination conditions. Table 2 summarizes dark and illumination current measured at $10 \mathrm{~V}$, as well as the ideality factor and $\mathrm{SBH}$ of the samples determined from the I-V measurements. By referring to Table 2, it is found that high temperature annealing in oxygen ambient $\left(600^{\circ} \mathrm{C}\right.$ and $\left.700{ }^{\circ} \mathrm{C}\right)$ resulted in more significant changes to the dark current characteristics compared to the lower temperature annealing treatment. High temperature annealing treatment increased the barrier height as well as reduced the dark current level. For lower annealing temperature $\left(400{ }^{\circ} \mathrm{C}\right.$ and $\left.500{ }^{\circ} \mathrm{C}\right)$, the barrier height for annealed samples (photodiodes) increased. As shown in Fig. 10, it can be seen that dark currents became significantly smaller after annealing. Such a reduction can again be attributed to the formation of $\mathrm{NiO}$ layers since $\mathrm{NiO}$ is p-type in nature (Averine et. al., 2000). As a result, we achieved larger Schottky barrier heights from the thermally annealed samples.

In the literatures, it can been seen that the bi-layer of $\mathrm{Ni} / \mathrm{Au}$ film annealed in oxygen by using photo-CVD would transform the metallic $\mathrm{Ni}$ into $\mathrm{NiO}$ along with $\mathrm{Au}$ grains and amorphous Ni-Ga-O phases (Chen et. al., 1999). Hence, the Ni/ Au semitransparent contact 


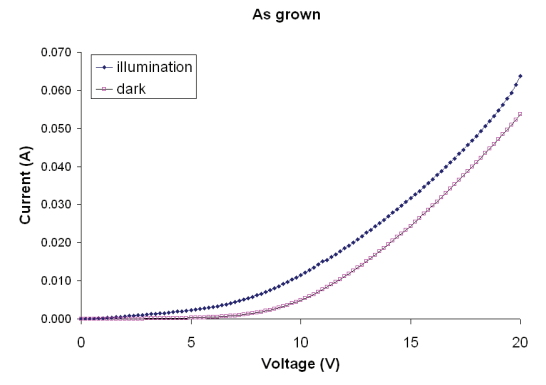

(a) As grown samples.

Annealed at $500 \mathrm{C}$

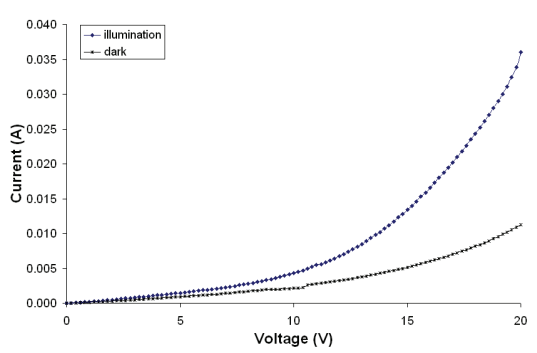

(c) Annealed at $500^{\circ} \mathrm{C}$.

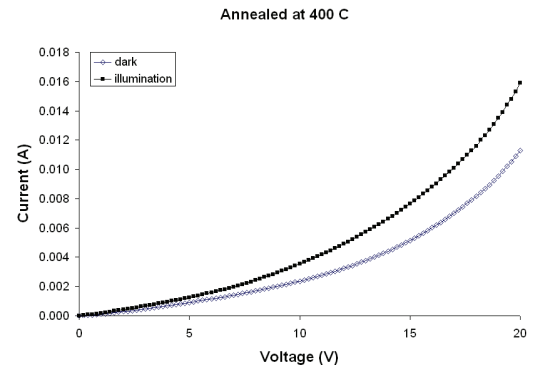

(b) Annealed at $400{ }^{\circ} \mathrm{C}$.

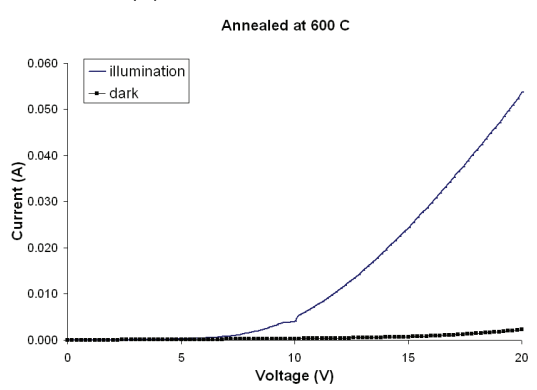

(d) Annealed at $600{ }^{\circ} \mathrm{C}$

Annealed at $700 \mathrm{C}$

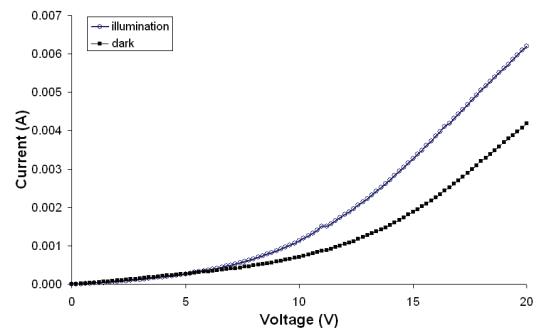

(e) Annealed at $700{ }^{\circ} \mathrm{C}$.

Fig. 10. Current-voltage (I-V) characteristics of Ni/AlGaN photodetectors under dark and illumination conditions (Chuah et. al., 2009b)

can be used to form good Schottky contacts with superior Schottky barrier height. In this study, the $\mathrm{Ni} / \mathrm{Al}_{0.09} \mathrm{Ga}_{0.91} \mathrm{~N}$ samples were annealed at a range of temperatures in flowing oxygen by using a tube furnace. $\mathrm{NiO}$, which is reported to behave as a p-type semiconductor with nickel vacancies and/or oxygen interstitials, has also been reported as a kind of passivation layer on the AlGaN interface (Kim et. al., 2006). As the annealed temperature increases, the transmittance increases. The increase of transmittance also indicates the formation of $\mathrm{NiO}$. We are able to achieve excellent photo-current to darkcurrent contrast ratio from the AlGaN MSM photodetectors, which can be attributed to the formation of the transparent $\mathrm{NiO}$ in the $\mathrm{Ni}$ contacts. It was found that dark current of the detector became significantly smaller after annealing. 
With a $10 \mathrm{~V}$ applied bias, it was found that we can achieve a photocurrent to dark current contrast ratio of 12 from the photodetectors with $600{ }^{\circ} \mathrm{C}$ annealed Ni contacts. This could be attributed to the more transparent nature of $\mathrm{NiO}$ formed after annealing so that more photons can be absorbed by the underneath AlGaN epitaxial layer. Such an effect should compensate the effect of larger Schottky barrier height. As the annealing temperature was increased to $700{ }^{\circ} \mathrm{C}$, it was found that we can achieve a photocurrent to dark current contrast ratio of 2, which may be due to the formation of a rough Ni layer surface. Such a rough surface could increase light scattering losses and thus degraded the film transparency.

On the other hand, for Ni/AlGaN Schottky contact, the effect of "surface patches" which originates from surface defects such as dislocations and micropipes with residual oxides may not be neglectable (Sawada et. al., 2000). Postannealing is an effective method to repair the surface patches. However, considering that the annealing temperature is relatively low and the time is short, the surface patches effect could not be regarded as the main factor to the enhancement of the barrier height. When the sample was under illumination condition, the change of current was significant for the annealed sample as compared to the as grown sample. Both as grown and annealed samples originated from the same AlGaN wafer, and both of the devices were fabricated using same processing tools and under identical parameters, however, significant difference in dark current was observed. High dark current in the as grown sample could be attributed to the low barrier height of the metal contact with the AlGaN thin film.

Since the Ni film became more transparent after annealing in $\mathrm{O}_{2}$, more photons should be absorbed by the underneath semiconductor. The oxidation layer near the interface provides an increasing energy barrier for carrier injection into AlGaN. As the oxidation temperature increases (annealed at $800{ }^{\circ} \mathrm{C}$ ), the rectifying characteristics is deteriorated by excess oxidation. There may be some interfacial reaction between oxygen and AlGaN. The real interaction is still under investigation.

The effect of the reduction of leakage current or dark current, barrier height or ideality factor enhancement in the MSM photodiodes after heat treatment can mainly be explained by the chemical reaction of the metal with the interfacial oxide layer of the semiconductor

\begin{tabular}{|c|c|c|c|c|}
\hline $\begin{array}{c}\text { Temperature } \\
\left({ }^{\circ} \mathrm{C}\right)\end{array}$ & $\begin{array}{c}\text { Samples } \\
\text { (MSM photodiodes) }\end{array}$ & $\begin{array}{c}\text { Ideality } \\
\text { factor, } \mathrm{n}\end{array}$ & $\begin{array}{c}\text { Barrier } \\
\text { height, } \\
\Phi_{\mathrm{b}}(\mathrm{eV})\end{array}$ & $\begin{array}{c}\text { Current at } \\
10 \mathrm{~V}(\mathrm{~A})\end{array}$ \\
\hline \multirow{2}{*}{ As grown } & illumination & 1.23 & 0.51 & $1.15 \times 10^{-2}$ \\
\cline { 2 - 5 } & dark & 1.20 & 0.53 & $4.94 \times 10^{-3}$ \\
\hline \multirow{2}{*}{$400^{\circ} \mathrm{C}$} & illumination & 1.15 & 0.55 & $3.54 \times 10^{-3}$ \\
\cline { 2 - 5 } & dark & 1.10 & 0.57 & $1.37 \times 10^{-3}$ \\
\hline \multirow{2}{*}{$500^{\circ} \mathrm{C}$} & illumination & 1.09 & 0.60 & $6.25 \times 10^{-3}$ \\
\cline { 2 - 5 } & dark & 1.08 & 0.61 & $2.15 \times 10^{-3}$ \\
\hline \multirow{2}{*}{$600^{\circ} \mathrm{C}$} & illumination & 1.05 & 066 & $4.04 \times 10^{-3}$ \\
\cline { 2 - 5 } & dark & 1.04 & 0.69 & $2.20 \times 10^{-4}$ \\
\hline \multirow{2}{*}{$700^{\circ} \mathrm{C}$} & illumination & 1.02 & 0.67 & $1.01 \times 10^{-3}$ \\
\cline { 2 - 5 } & dark & 1.01 & 0.70 & $7.09 \times 10^{-4}$ \\
\hline
\end{tabular}

Table 2. Summary of the dark current characteristics of the samples annealed in oxygen ambient at different temperatures. 
(Abdulmecit et. al., 1992) or macroscopic interaction between the metal and the semiconductor (Liu et. al, 1998). Experimental results also revealed that reactive contact metals decrease the interfacial layer and react with the semiconductor during annealing and hence it can cause a low or high barrier height for the MSM photodiodes.

It can be viewed that dark current increased gradually with the applied reverse bias and does not exhibit any impact of saturation. The absence of saturation for a Schottky contact under reverse bias could be clarified in terms of barrier height which is dependent on the electric field strength in the barrier as a result of the existence of an interfacial layer between the metal and the semiconductor. Besides that, the lack of saturation might be caused by image force lowering of the barrier height and because of the generation of electron-hole pairs in the depletion region as generation current is more pronounced at low temperatures than high temperatures because it has lower activation energy than the thermionic emission component (Rhoderick et. al., 1988).

$\mathrm{Al}_{0.09} \mathrm{Ga}_{0.91} \mathrm{~N}$ is known to experience from a high volume of defect densities due to the reasons like the difference between the thermal expansion coefficient and large lattice mismatch between the silicon substrates and the $\mathrm{Al}_{0.09} \mathrm{Ga}_{0.91} \mathrm{~N}$ material. During the reverse bias of the Schottky contact, the effect of the applied bias can be much greater when compared to the forward bias. Thus, tunneling current can also be observed in a semiconductor with a lower doping concentration during reverse biases which mean that the tunnel current cannot be left out when investigating Schottky contacts under reverse bias voltage.

Consequently, apart from the usual thermionic emission current that survive within a metalsemiconductor contact, the high amount of dark current observed can be attributed to the tunneling of carriers across the barrier. This effect can be assisted by traps generated by defects (threading dislocations that reach the surface) and the interfacial layer to produce trap assisted tunnel currents. Deep level bulk states that are within a tunneling distance of the interface can be another kind of traps. Therefore, thermionic emission is the primary transport mechanism in these MSM photodiodes.

Another contribution to the high dark current in $\mathrm{Al}_{0.09} \mathrm{Ga}_{0.91} \mathrm{~N}$ is dominated by other current mechanism like leakage current generated by a high defect density present in $\mathrm{Al}_{0.09} \mathrm{Ga}_{0.91} \mathrm{~N}$ as well as the traps assisted tunnel current. The high defect density in $\mathrm{Al}_{0.09} \mathrm{Ga}_{0.91} \mathrm{~N}$ justifies the presence of inhomogeneity at Schottky contacts, which causes a local enhancement of the tunnel current. The rotation of the layer during the growth and the different positions of the III-element sources could produce alloy inhomogeneities, as already reported.

From the results, the value of the ideality factor is quite near to unity, thus indicating the high quality Schottky contact under investigation and the absence of a thick interfacial layer. However, the existence of a thin interfacial layer cannot be ruled out unless the semiconductor is cleaved in an ultra high vacuum (UHV) condition (Guo et. al., 1996). The variation in barrier height values may be due to formation of alloy, different thickness of interfacial layer present on the film, variation in surface roughness of samples used, defects present in films, presence of several transport mechanism, and the variations in the local stoichiometry (Pearton et. al., 1999).

\section{Conclusions}

In the previous years, GaN growth on $\mathrm{Si}$ has expanded fastly and a few solutions are emerging to adjust the stress because of the thermal mismatch. In recent years, many groups 
have obtained thick, crack-free $\mathrm{GaN}$ on $\mathrm{Si}$ (111) by molecular beam epitaxy (MBE) or metalorganic chemical vapor deposition (MOCVD). There are also some reports about devices fabricated on GaN/Si (111) such as light emitting diodes (LEDs) and high electron mobility transistors (HEMTs). PN heterojunction photodiode, metal-semiconductor-metal (MSM) photodetectors, and Schottky photodiodes are now well developed and expected to be commercialized soon. However, reports of photodetectors based on crack-free GaN on Si (111) are limited. In the near future, Si may be the predominant substrate material for GaN growth because of its low price and availability in large diameters. The further interest is that the $\mathrm{Si}$ substrate can be etched away for laser or LEDs and for development of GaN substrates.

\section{Acknowledgement}

Support from RU grant and Universiti Sains Malaysia is gratefully acknowledged.

\section{References}

Abdulmecit Turut, Sebahattin Tuzemen, Muhammet Yildirim, Bahattin Abay, and Mustafa Saglam, (1992) Barrier height enhancement by anealing $\mathrm{Cr} / \mathrm{Ni} / \mathrm{Co}$ alloy Schottky contacts on LEC GaAs, Solid-State Electron., 35(10), pp. 1423 - 1426.

An Doan, (2002) Studies of Minority Carrier Recombination Mechanisms in Be Doped GaAs for Optimal High Speed LED Performance.

Averine, S., Chan, Y. C., Lam, Y. L.; (2000) Evaluation of Schottky contact parameters in metalsemiconductor-metal photodiode structures, Appl. Phys. Lett., 77(2), pp. 274 - 276.

BenMoussa, A.; Hochedez, J.F.; Dahal, R.; Li, J.; Lin, J. Y.; Jiang, H.X.; Soltani, A.; Jaeger, J-C. De; Kroth, U.; Richter, M.; (2008) Characterization of AlN metal-semiconductormetal diodes in the spectral range of 44-360 nm: Photoelission assessments, Appl. Phys. Lett., 92, pp. 022108-0221011.

Casey Jr., H.C.; Fountain, G.G.; Alley, R.G.; Keller, B.P.; DenBaars, S.P.; (1996) Low interface trap density for remote plasma deposited $\mathrm{SiO}_{2}$ on n-type $\mathrm{GaN}$, Appl. Phys. Lett., Vol. 68, Issue 13, pp. 1850-1852.

Chang, P.C.; Chen, C.H.; Chang, S.J.; Su, Y.K.; Yu, C.L.; Chen, P.C.; Wang, C. H.; (2004) AlGaN/GaN MSM photodetectors with photo-CVD aneealed Ni/Au semitransparent contacts, Semicond. Sci. Technol. Vol. 19, No. 12, pp. 1354-1357.

Chen, L.C. ; Chen, F.R. ; Kai, J.J. ; Chang, Li; Ho, J.K,; Jong, C. S.; Chiu, C.C.; Huang, C. N.; Chen, C. Y.; Shih, K. K. (1999) Microstructural investigation of oxidized Ni/Au ohmic contact to p-type GaN, J. Appl. Phys. 86, pp.3826- 3832.

Chen, L.C.; Fu, M.S.; Huang, I.L. ; (2004) Metal-semiconductor-Metal AlN Mid-Ultraviolet Photodetectors grown by Magnetron reactive sputtering deposition, Japanese Journal of Applied Physics, vol. 43, No. 6A, pp. 3353-3355.

Chuah, L.S.; Hassan, Z.; Abu Hassan, H.; Hussein Mourad, M.; (2008a) p-GaN/n-Si heterojunction photodiodes, Surface Review and Letters, Vol. 15, pp. 699-703.

Chuah, L.S.; Hassan, Z.; Abu Hassan, H.; Yam, F.K.; Chin, C.W.; Thahab, S. M.; (2008b) Barrier height enhanced GaN Schottky diodes using a thin AlN surface layer, International Journal of Modern Physics B, Vol. 22, pp. 5167-5173.

Chuah, L.S.; Hassan, Z.; Abu Hassan, H.; Chin, C.W.; Thahab, S.M.; (2008c) Large area GaN metal semiconductor metal (MSM) photodiode using a thin low temperature GaN cap layer, Journal of Nonlinear Optical Physics and Materials, Vol. 17, pp. 59 - 69. 
Chuah, L.S.; Hassan, Z.; Abu Hassan, H.; Ahmed, N. M.; (2009a) GaN Schottky barrier photodiode on $\mathrm{Si}(111)$ with low-temperature-grown cap layer, Journal of Alloys and Compounds, Vol. 481, pp. L15-L19.

Chuah, L.S.; Hassan, Z.; Abu Hassan, H.; (2009b) The effects of annealing treatment in oxygen ambient on $\mathrm{Ni} / \mathrm{Al}_{0.09} \mathrm{Ga}_{0.91} \mathrm{~N}$ UV photodetectors, Journal of Optoelectronics and Advanced Materials, Vol. 11, No. 5, pp. 76-82.

Edgar, J.H.; Strike, S.; Akasaki, I.; Amano H., Wetzel C. (1999) : Properties: Processing and application of Gallium Nitride and related semiconductor, INSPEC, London.

Fahrettin Yakuphanoglu, (2008) analysis of interface states of metal-insulator-semiconductor photodiode with n-type silicon by conductance technique, Sensors and Actuators A: Physical , vol. 147 pp. 104-109.

Gaffey, B.; Guido, L.J. ; Wang, X.W. ; Ma, T.P. ; (2001) High-quality oxide/nitride/oxide gate insulator for GaN MIS structures, IEEE Trans. Electron Dev., Vol. 48, pp. 458 - 464.

Guo, J. D.; Pan, F. M.; Feng, M. S.; Guo, R. J.; Chou, P. F.; Chang, C. Y.; (1996) Schottky contact and the thermal stability of Ni on n-type GaN, J. Appl. Phys., 80(3), pp. 1623-1628.

Hacke, P.; Detchprohm, T.; Hiramatsu, K.; Sawaki, N.; (1993) Schottky barrier on n-type GaN grown by hydride vapor phase epitaxy, Appl. Phys. Lett., 63, pp. 2676 -2678.

Hassan, Z.; Lee, Y.C.; Yam, F.K.; Abdullah, M.J.; Ibrahim, K.; Kordesch, M.E. (2004) Microcrystalline GaN film grown on $\mathrm{Si}(100)$ and its application to MSM photodiode, Mater. Chem. Phys., Vol. 84, pp. 369-374.

He, J. H.; Ho, S. T.; Wu, T. B.; Chen, L.J.; Wang, Z. L.; (2007) Electrical and photoelectrical performances of nano-photodiode based on $\mathrm{ZnO}$ nanowires, Chemical Physics Letters, vol. 435, pp. 119-122.

Kalinina, E.V., Kuznetsov, N.I., Babanin, A.I., Dmitriev, V.A.; Shchukarev, A.V.; (1997) Structural and electrical properties of Schottky barriers on n-GaN, Diamond Relat. Mater. Vol. 6, Issue 10, pp. 1528- 1531.

Keem, K.; Kim. H.; Kim, G.T.; Lee, J.S.; Min, B.; Cho. K.; Sung, M.Y.; Kim, S.; (2004) Photocurrent in znO nanowires grown from Au electrodes, Appl. Phys. Lett., 84, pp. 4376-4378.

Khanna, R.; Pearton, S.J. ; Ren, F.; Kravchenko, I. (2006) Annealing and measurement temperature dependence of W2B5-based rectifying contacts to n-GaN, Appl. Surf. Sci., 252, pp. 5814- 5819.

Kim, K.; Lambrecht, W. R. L.; Segall, B.; Schilfgaarde, M. V.; (1997) Effective masses and valence-band splittings in GaN and AlN, Phys. Rev. B, 56, pp. 7363-7375.

Kim, H.; Schuette, M.; Jung, H.; Song, J.H.; Lee, J.; Lu, W. (2006) Passivation effects in Ni/AlGaN/GaN Schottky diodes by annealing, Appl. Phys. Lett., 89, pp. 053516053519.

Lee, Y.C.; Hassan, Z.; Abdullah, M.J.; Hashim, M.R.; Ibrahim, K. (2005) Dark current characteristics of thermally treated contacts on GaN-based ultraviolet photodetectors, Microelectronics Engineering, vol 81, pp. 262-267.

Lee, M.L.; Sheu, J.K; Lin, S.W.; (2006) Schottky barrier heights of metal contacts to n-type gallium nitride with low-temperature-grown cap layer, Applied Physics letters, 88, pp. 032103-032106.

Liu, Q. Z.; Yu, L. S. ; Deng, F.; Lau, S. S.; Redwing, J. M.; (1998) Ni and Ni silicide Schottky contacts on $n-\mathrm{GaN}$, J. Appl. Phys., 84, pp. 881-887. 
Luo, L.; Zhang, Y.F.; Mao, S. S.; Lin, L.W.; (2006) Fabrication and characterization of ZnO nanowires based UV photodiodes, Sensors and Actuators A, 127, pp. 201-206.

Miskys, C. R.; Kelly, M. M; Ambacher, O.; Stutmann, M., (2003) Freestading GaN-substrates and devices, Phys. Stat. Sol. (C), 6, pp. $1627-1650$.

Monroy, E.; Munoz, E.; Sanchez, F.J.; Calle, F.; Calleja, E.; Beaumont, B.; Gibart, P.; Munoz, J.A.; Cusso, F.; (1998) High-performance GaN p-n junction photodetectors for solar ultraviolet applications, Semicond. Sci. Tech., 13, pp. 1042 - 1046.

Pearton, S. J.; Zolper, J. C.; Shul, R. J. ; Ren, F. (1999) GaN: Processing, defects, and devices, J. Appl. Phys, vol. 86, Issue 1, pp. 1-78.

Piotr Perlin, Tadeusz Suski, Michal Leszczynski, and Henryk Teisseyre (1997) GaN and Related Materials, edited by S. J. Pearton, (Gordon and Breach Science Publishers, Amsterdam.

Philippe, A.; Bru-chevallier, C.; Gamez-cuatzin, H.; Guillot, G.; Martinez-Guerrero, E.; Feuillet, G. ; Daudin, B.; Aboughe-Nze, P.; Monteil, Y.; (1999) Optical study of cubic gallium nitride band-edge and relation with residual strain, Phys. Stat. Sol. (B), vol. 216, Issue 1, pp. 247- 252.

Reddy, V.R.; Rao, P.K.; Ramesh, C.K.; (2007) Annealing effects on structural and electrical properties of $\mathrm{Ru} / \mathrm{Au}$ on $\mathrm{n}-\mathrm{GaN}$ Schottky contacts, Material Science and Engineering B, 137, pp. 200 - 204.

Rhoderick, E. H.; Williams, R. H.; (1988) Metal-Semiconductor Contacts, second ed., Oxford University Press, New York.

Rideout, V. L.; (1975) A review of the theory and technology for ohmic contacts to group IIIV compound semiconductors, Solid-State Electron., Vol. 18, Issue 6, pp. 541- 550.

Qioa, D.; Yu, L.S.; Lau, S. S.; Redwing, J. M.; Lin, J. Y. Lin; Jiang, H.X.; (2000) Dependance of $\mathrm{Ni} / \mathrm{AlGaN}$ Schottky barrier height on Al mole fraction, Journal of Applied Physics, 87 (2000) pp. 801-804.

Vivian K.X. Lin; Esther Alarcon-Llado; Kim, H.H.; Arulkumaran, S.; Ng, G.I.; Raman, A.; Tripathy, S.; (2010) Structural and electrical characterization of AlxGa1-xN/GaN Interfaces for UV Photodetectors, Electrochem. Solid-State Lett., Vol. 13, Issue 9, pp. H301-304.

Wang, J.; Zhao, D.G.; Sun, Y.P.; Duan, L.H.; Wang, Y.T.; Zhang, S.M.; Yang, H.; Zhou, S.; Wu, M.; (2003) Thermal annealing behavior of Pt on n-GaN Schottky contacts, J. Phys D: Appl. Phys., vol. 36, pp. 1018-1022.

Sawada, T.; Ito, Y.; Imai, K.; Suzuki, K.; Tomozawa, H.; Sakai, S.; (2000) Electrical properties of metal/GaN and $\mathrm{SiO}_{2} / \mathrm{GaN}$ interfaces and effects of thermal annealing, Appl. Surf. Sci, 159/160, pp. 449-455.

Schmitz, A.C.; Ping, A.T.; Asif Khan, M.; Chen, Q.; Yang, J.W.; Adesida, I.; (1996) Schottky barrier properties of various metals on n-type GaN, Semicond. Sci. Technol., 11, pp. 1464 - 1467.

Soci, C., Zhang, A., Bao, X.Y.; Kim, H.K.; Lo, Y.; Wang, D.; (2010) Nanowire photodetectors, Journal of Nanoscience and Nanotechnology, Vol. 10, pp. 1-20.

Sze, S.M. (1981) Physics of Semiconductor Devices, $2^{\text {nd }}$ ed., Wiley, New York.

Yeh, D.H.; Hsieh, L.Z.; Chang, L.B.; Jeng, M. J.; (2007) The characteristics of platinum diffusion in n-type GaN, Applied Surface Science, 253, pp. 6910-6914.

Yu, C.L.; Chang, S.J.; Chang, P.C.; Lin, Y.C.; Lee, C. T.; (2006) Nitride-based ultraviolet Schottky barrier photodetectors with LT-AlN cap layers, Superlattices and Microstructures, vol. 40, pp. 470-475. 


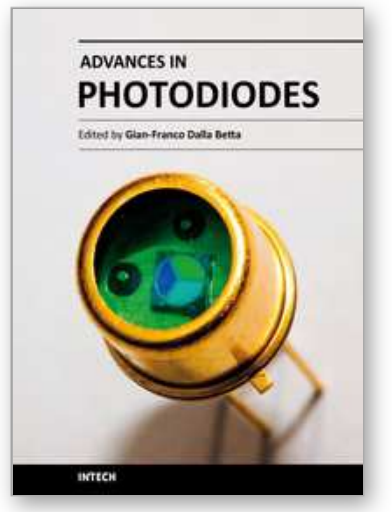

\author{
Advances in Photodiodes \\ Edited by Prof. Gian Franco Dalla Betta
}

ISBN 978-953-307-163-3

Hard cover, 466 pages

Publisher InTech

Published online 22, March, 2011

Published in print edition March, 2011

Photodiodes, the simplest but most versatile optoelectronic devices, are currently used in a variety of applications, including vision systems, optical interconnects, optical storage systems, photometry, particle physics, medical imaging, etc. Advances in Photodiodes addresses the state-of-the-art, latest developments and new trends in the field, covering theoretical aspects, design and simulation issues, processing techniques, experimental results, and applications. Written by internationally renowned experts, with contributions from universities, research institutes and industries, the book is a valuable reference tool for students, scientists, engineers, and researchers.

\title{
How to reference
}

In order to correctly reference this scholarly work, feel free to copy and paste the following:

L.S. Chuah and Z. Hassan (2011). GaN-based Photodiodes on Silicon Substrates, Advances in Photodiodes, Prof. Gian Franco Dalla Betta (Ed.), ISBN: 978-953-307-163-3, InTech, Available from:

http://www.intechopen.com/books/advances-in-photodiodes/gan-based-photodiodes-on-silicon-substrates

\section{INTECH}

open science | open minds

\section{InTech Europe}

University Campus STeP Ri

Slavka Krautzeka 83/A

51000 Rijeka, Croatia

Phone: +385 (51) 770447

Fax: +385 (51) 686166

www.intechopen.com

\section{InTech China}

Unit 405, Office Block, Hotel Equatorial Shanghai

No.65, Yan An Road (West), Shanghai, 200040, China

中国上海市延安西路65号上海国际贵都大饭店办公楼 405 单元

Phone: +86-21-62489820

Fax: +86-21-62489821 
(C) 2011 The Author(s). Licensee IntechOpen. This chapter is distributed under the terms of the Creative Commons Attribution-NonCommercialShareAlike-3.0 License, which permits use, distribution and reproduction for non-commercial purposes, provided the original is properly cited and derivative works building on this content are distributed under the same license. 